\title{
CORRELATIONS BETWEEN PHYSICAL PROPERTIES AND POINT LOAD STRENGTH INDEX OF PRASINITES: A CASE STUDY FROM EAST ATTICA PREFECTURE
}

\author{
Kotsanis D. ${ }^{1}$, Nomikos P.P. ${ }^{2}$, Rozos D. ${ }^{1}$ and Sofianos A.I. ${ }^{2}$ \\ ${ }^{I}$ National Technical University of Athens, School of Mining \& Metallurgical Engineering, \\ Laboratory of Engineering Geology and Hydrogeology, 15780, Athens, Greece, \\ dkotsanis@metal.ntua.gr,rozos@metal.ntua.gr \\ ${ }^{2}$ National Technical University of Athens, School of Mining \& Metallurgical Engineering, \\ Tunneling Laboratory, 15780, Athens, Greece,nomikos@metal.ntua.gr, sofianos@metal.ntua.gr
}

\begin{abstract}
The aim of this study is to investigate the statistical correlations between the point load strength index and certain physical properties, e.g. the dry density and the dry longitudinal ultrasonic wave velocity of prasinites (metabasites). Statistically significant correlations established between the physical properties as well as between each physical quantity and the point load strength index. According to bibliography, this is one of the first efforts to develop relations between physical and mechanical properties for this particular petrological type, and therefore the derived equations can be a useful tool to the investigation of these petrological types, either in the study area or in other sites, where prasinites of similar structural characteristics, are examined for the foundation of various constructions.

Keywords: Density, Ultrasonic wave velocity, Mechanical properties, Statistical relationships, Metabasites.
\end{abstract}

\section{Пврі́ $\eta \psi \eta$}

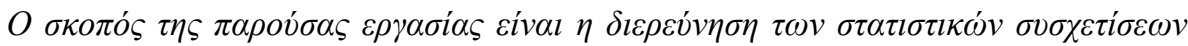

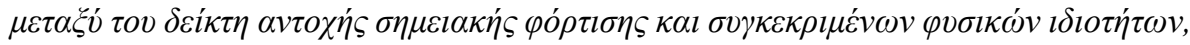

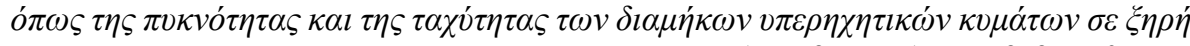

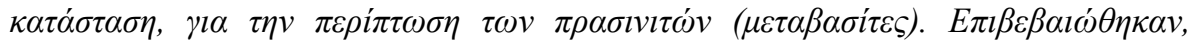

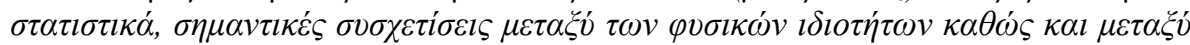

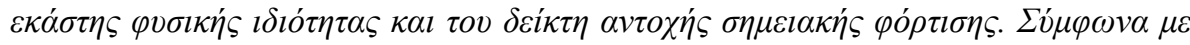

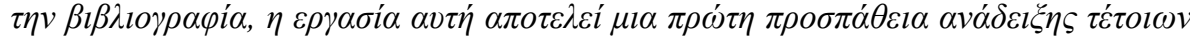

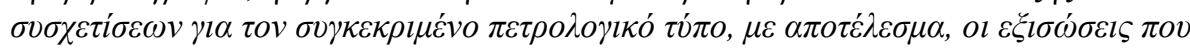

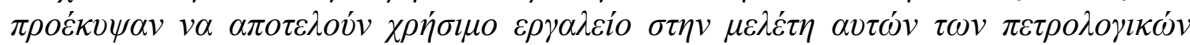

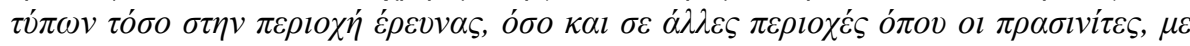

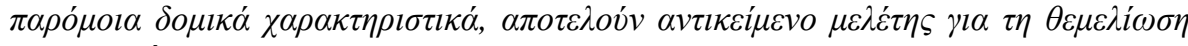

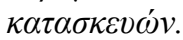

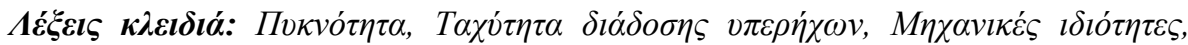
$\Sigma \tau \alpha \tau \imath \sigma \tau \iota \kappa \varepsilon ́ \varsigma \sigma v \sigma \chi \varepsilon \tau i \sigma \varepsilon ı \varsigma, ~ M \varepsilon \tau \alpha \beta \alpha \sigma i \tau \varepsilon \varsigma$. 


\section{Introduction}

Since the fundamental work of (Broch and Franklin, 1972) and (Guidicini et al., 1973), the point load test obtained considerable attention in the geotechnical practice, due to its simplicity and inexpensive use. The point load strength index (Is) can be used for strength classification of the intact rock (Bieniawski, 1975), as well as an input parameter in the RMR classification system (Bieniawski, 1989). Despite the tensile nature of the test, several researchers have investigated the relationship between the point load strength index and unconfined compressive strength. In the study of Fener et al. (2005), the interested reader can find and assess numerous empirical equations for a variety of rock types.

It is a common and at the same time challenging task in the geotechnical engineering, trying to establish empirical correlations between measures of rock strength and intrinsic properties which control the strength of the intact rock. A number of researchers, (e.g., Irfan and Dearman, 1978, Pasamehmetoglu et al., 1981; Beavis, 1985; Rozos, 1989; Augustinus, 1991; Gupta and Seshagiri Rao, 1998; Palchik and Hatzor, 2004; Shafiei et al., 2007; Kurtulus et al., 2012; Altindag, 2012) have investigated the relationship among some physical property like the absolute or effective porosity, the specific gravity and the longitudinal ultrasonic wave velocity with the point load strength index. In the aforementioned studies, irrespectively of the mathematical formulation e.g. linear, exponential or power, the common trend is the reduction of the point load strength index as the porosity increases and the increase of the index as the density or the wave velocity increases.

The objective of this study is to derive new correlation equations between the dry density and dry longitudinal ultrasonic wave velocity with the size corrected point load strength index $\operatorname{Is}_{(50)}$, obtained from axial point load tests, in the case of prasinites. For this reason, a total of fourteen (14) rock samples were collected from the area of East Attica Prefecture and sixty-eight (68) rock disks prepared and tested. The results were analyzed using ordinary least squares regression and the derived equations proved to be statistically significant with strong coefficients of determination.

\section{Location and Geological Aspects of the Study Area}

The geographical distribution of the collected rock samples is shown in Figure 1. The study area is located in the south part of the East Attica Prefecture and extends from north to south between the sites of Ano Daskalio village and Sounio town. The bodies of prasinites (metabasites) belongs to the so called Neo - Hellenic Nappe (Katsikatsos, 1992), as intercalations within the formations of phyllites, schists and quartzites. Their maximum thickness can reach up to $50 \mathrm{~m}$. They are poorly foliated and can be categorized either as bluschists or greenschists with the later to be the predominant rock type (Baziotis et al., 2008).

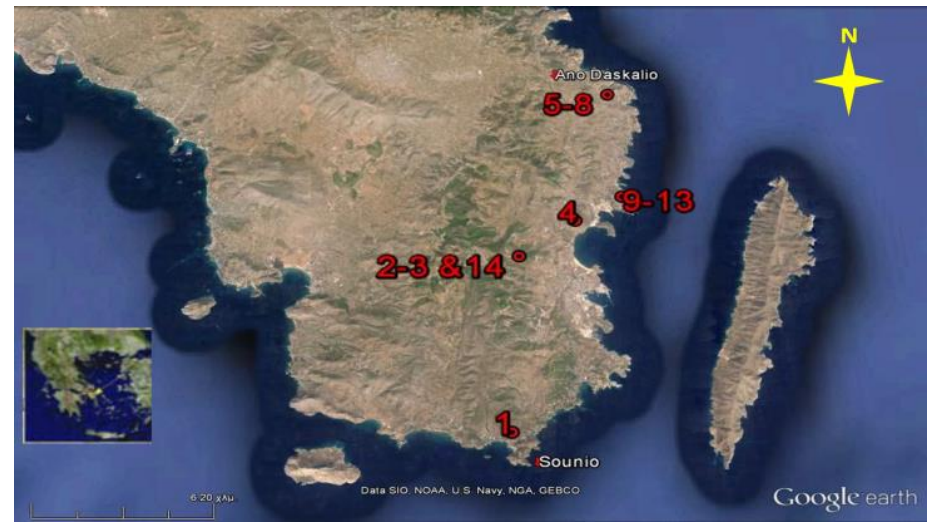

Figure 1 - Location of samples (Numbers refers to rock codes). 
In the field, prasinites appeared as massive relatively fresh formations, in cases with a dense net of calcite veins and at some places intensively fractured and weathered due to the presence of the soluble calcite veins. (Fig. 2).
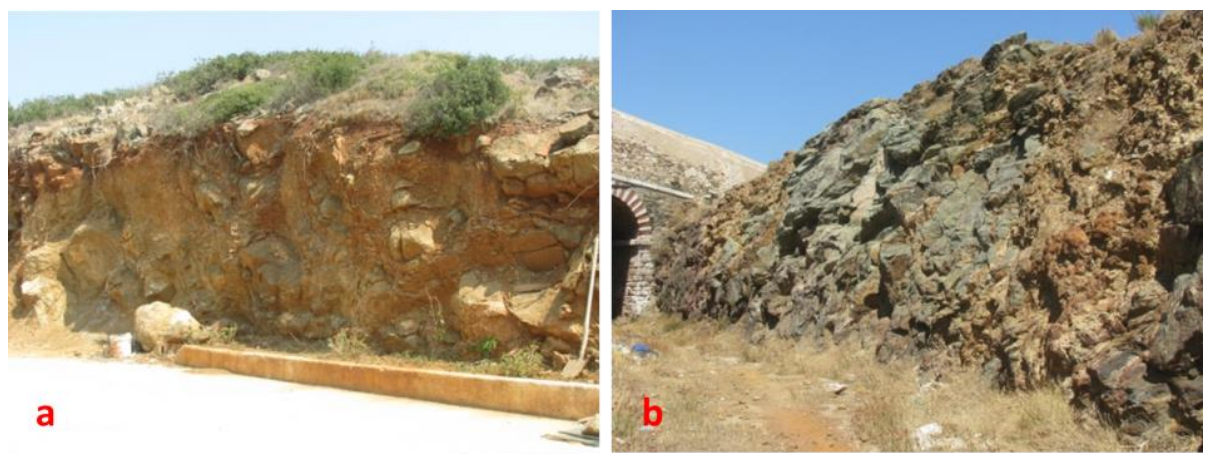

Figure 2 - (a) Intensively fractured and weathered prasinites, (b) Fresh prasinites.

\section{Experimental Procedure and Results}

The fourteen (14) rock blocks collected, helped to produce a total number of sixty-eight (68) right circular disks of NX diameter. These disks were prepared in accordance with the suggested methods of ISRM (ISRM, 1981a). The collection of specimens was performed in such a way, to capture, as much as possible, the whole spectrum of the weathering characteristics of the formation (Fig. 3), in order to result in statistically significant correlations. Samples with distinct features of foliation were excluded from the statistical analysis in order to avoid the influence of anisotropy to the wave propagation.

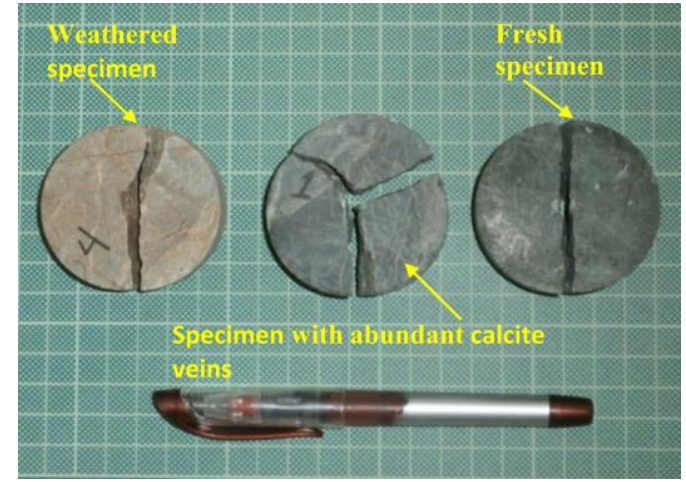

Figure 3 - Prasinites with various stages of weathering.

\subsection{Dry Density}

The dry density was measured after the oven - drying of the specimens at $40^{\circ} \mathrm{C}$ for several days until to get a constant mass. In spite of the suggested methods of ISRM (ISRM, 1981a), for the determination of the dry density, the temperature was set at this level, in order to avoid any thermal degradation due to the presence of calcite in the mineralogical composition. After the oven-drying the specimens were placed in a desiccator for two days to reach up temperature equilibrium.

The values of dry density range between $2.565 \mathrm{gr} / \mathrm{cm}^{3}$ and $2.983 \mathrm{gr} / \mathrm{cm}^{3}$ and the inherent variability of the selected samples is shown as box plots in Figure 4.

According to IAEG classification (Table 1 - Anon, 1979), the prasinites in the study area are classified as formations of high up to very high dry density. 
Table 1 - Dry density classes for hard and soft rocks (Anon, 1079).

\begin{tabular}{|l|c|c|}
\hline Class & Range $\left(\mathbf{g r} / \mathbf{c m}^{\mathbf{3}}\right)$ & Term \\
\hline 1 & $<1.80$ & Very Low \\
\hline 2 & $1.80-2.20$ & Low \\
\hline 3 & $2.20-2.55$ & Moderate \\
\hline 4 & $2.55-2.75$ & High \\
\hline 5 & $>2.75$ & Very High \\
\hline
\end{tabular}

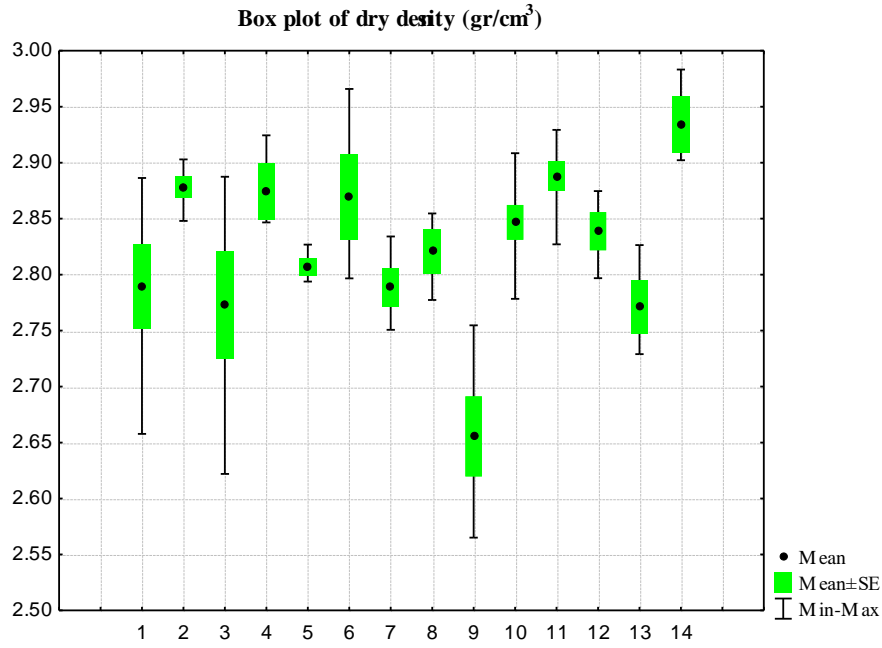

Figure 4 - Box plot of dry density of examined samples.

\subsection{Dry Longitudinal Ultrasonic Wave Velocity}

This property is very sensitive to various structural characteristics of a rock, like the mineralogical composition, grain size, porosity, joints, cracks and anisotropy. In the ultrasonic pulse method, the wave speed is calculated by dividing the distance between the transmitter and the receiver by the time required for the transient pulse to travel this distance. In the present study a Pundit testing instrument was used, equipped with transducers of $150 \mathrm{kHz}$ dominant frequency. The configuration of direct transmission was used and further details of the experimental procedure were in line with the upgraded suggestions of ISRM. (Aydin, 2015).

The dry longitudinal ultrasonic wave velocity ranges from $3.947 \mathrm{~km} / \mathrm{s}$ up to $6.540 \mathrm{~km} / \mathrm{s}$ (Fig. 5). This variation is attributed to the various states of weathering and also to the presence of a dense net of calcite veins in a number of rock samples.

According to IAEG classification (Table 2 - Anon, 1979), the prasinites in the study area are classified as formations of moderate up to very high dry longitudinal ultrasonic wave velocity. 
Table 2 - Dry longitudinal ultrasonic wave velocity classes for hard and soft rocks (Anon, 1979).

\begin{tabular}{|l|c|c|}
\hline Class & Range $(\mathbf{k m} / \mathbf{s})$ & Term \\
\hline 1 & $<2.5$ & Very Low \\
\hline 2 & $2.5-3.5$ & Low \\
\hline 3 & $3.5-4.0$ & Moderate \\
\hline 4 & $4.0-5.0$ & High \\
\hline 5 & $>5.0$ & Very High \\
\hline
\end{tabular}

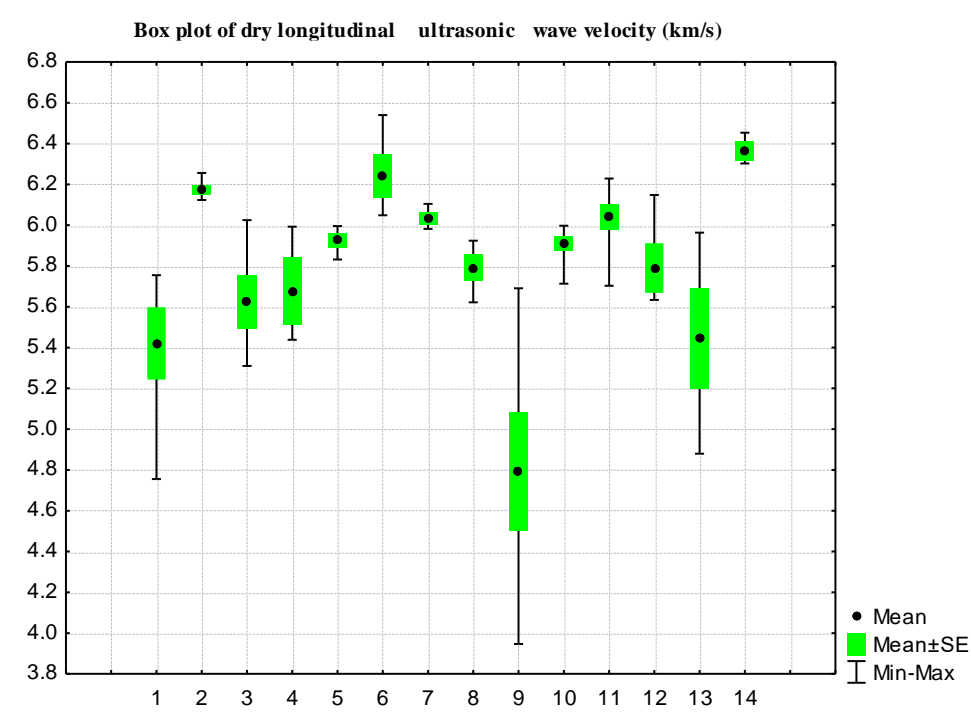

Figure 5 - Box plot of dry longitudinal ultrasonic wave velocity of examined samples.

\subsection{Point Load Strength Index Is $\mathbf{s}_{(50)}$}

After the determination of the physical and acoustical properties the specimens were tested in a portable machine of $50 \mathrm{kN}$ load capacity in order to obtain the axial point load strength index Is and hence the corrected one $\mathrm{Is}_{(50)}$. The experimental procedure and the relevant calculations were in accordance with the suggested methods of ISRM (ISRM, 1985b).

The corrected point load strength index $\mathrm{Is}_{(50)}$ shows a wide scatter, as shown in Figure 6, with values between 1.64 $\mathrm{MPa}$ and $13.71 \mathrm{MPa}$, characterising the material's strength, according to the classification of Bieniawski ( Table 3 - Bieniawski, 1975) as low up to very high.

Table 3 - Rock materials classification according to PLS index (Bieniawski, 1975).

\begin{tabular}{|c|c|}
\hline Description & Point load strength index (MPa) \\
\hline Very high strength & $>8$ \\
\hline high strength & $4-8$ \\
\hline Medium strength & $2-4$ \\
\hline Low strength & $1-2$ \\
\hline Very low strength & $<1$ \\
\hline
\end{tabular}


The coefficient of variation, a dimensionless measure of variability in the test results (CoV \%) range between $3.52 \%$ up to $35.45 \%$ and is thought to be adequate for practical geotechnical applications (Kahraman and Gunaydin, 2009).

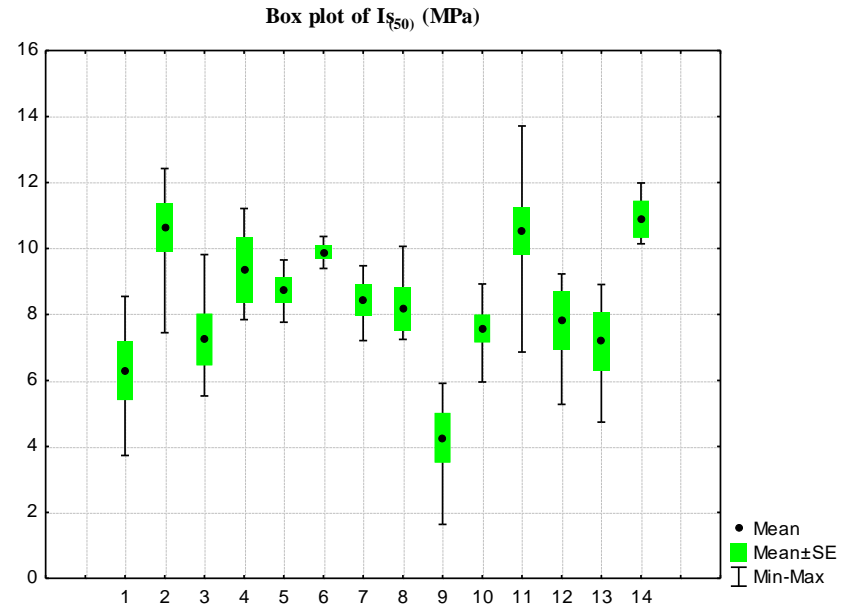

Figure 6 - Box plot of Is(50) of examined samples.

\section{Statistical Analysis}

The descriptive statistics, e.g. the mean, the standard deviation (SD) and the coefficient of variation $(\mathrm{CoV})$ of the physical and mechanical properties for each one of the fourteen (14) selected samples are summarized in Table 4.

Table 4 - Descriptive statistics of the physical and mechanical properties.

\begin{tabular}{|l|c|c|c|c|c|c|}
\hline \multirow{2}{*}{ code } & \multicolumn{2}{|c|}{ Dry Density } & \multicolumn{2}{c|}{ Dry Lon. Ult. Wave Vel. } & \multicolumn{2}{c|}{ Is(50) } \\
\cline { 2 - 7 } & $\begin{array}{c}\text { Mean } \pm \text { SD } \\
(\mathbf{g r} / \mathbf{c m 3})\end{array}$ & $\begin{array}{c}\mathbf{C o V} \\
(\boldsymbol{\%})\end{array}$ & $\begin{array}{c}\text { Mean } \pm \text { SD } \\
(\mathbf{k m} / \mathbf{s})\end{array}$ & $\begin{array}{c}\text { CoV } \\
(\%)\end{array}$ & $\begin{array}{c}\text { Mean } \pm \text { SD } \\
(\mathbf{M P a})\end{array}$ & $\begin{array}{c}\text { CoV } \\
(\%)\end{array}$ \\
\hline 1 & $2.790 \pm 0.074$ & 2.67 & $5.420 \pm 0.353$ & 6.52 & $6.30 \pm 1.79$ & 28.46 \\
\hline 2 & $2.878 \pm 0.022$ & 0.75 & $6.171 \pm 0.047$ & 0.76 & $10.63 \pm 1.62$ & 15.28 \\
\hline 3 & $2.773 \pm 0.096$ & 3.45 & $5.623 \pm 0.261$ & 4.65 & $7.24 \pm 1.57$ & 21.67 \\
\hline 4 & $2.875 \pm 0.035$ & 1.23 & $5.677 \pm 0.233$ & 4.10 & $9.35 \pm 1.40$ & 14.97 \\
\hline 5 & $2.807 \pm 0.013$ & 0.46 & $5.925 \pm 0.061$ & 1.04 & $8.74 \pm 0.67$ & 7.66 \\
\hline 6 & $2.870 \pm 0.066$ & 2.29 & $6.242 \pm 0.182$ & 2.92 & $9.88 \pm 0.35$ & 3.52 \\
\hline 7 & $2.789 \pm 0.030$ & 1.07 & $6.032 \pm 0.052$ & 0.85 & $8.44 \pm 0.82$ & 9.69 \\
\hline 8 & $2.821 \pm 0.034$ & 1.20 & $5.791 \pm 0.111$ & 1.92 & $8.17 \pm 1.13$ & 13.84 \\
\hline 9 & $2.655 \pm 0.072$ & 2.70 & $4.793 \pm 0.576$ & 12.02 & $4.26 \pm 1.51$ & 35.45 \\
\hline 10 & $2.847 \pm 0.044$ & 1.56 & $5.911 \pm 0.029$ & 0.49 & $7.58 \pm 1.15$ & 15.14 \\
\hline 11 & $2.888 \pm 0.039$ & 1.34 & $6.040 \pm 0.191$ & 3.16 & $10.53 \pm 2.15$ & 20.45 \\
\hline 12 & $2.839 \pm 0.030$ & 1.04 & $5.790 \pm 0.210$ & 3.62 & $7.82 \pm 1.51$ & 19.37 \\
\hline 13 & $2.731 \pm 0.041$ & 1.48 & $5.444 \pm 0.427$ & 7.84 & $7.19 \pm 1.52$ & 21.15 \\
\hline 14 & $2.934 \pm 0.035$ & 1.20 & $6.362 \pm 0.066$ & 1.03 & $10.89 \pm 0.79$ & 7.30 \\
\hline
\end{tabular}

The mean values of the above results were analyzed using the method of ordinary least squares regression, implemented in Matlab 12 . The equation of the best fit along with the $\pm 95 \%$ prediction 
bounds of the function and the coefficient of determination $\left(\mathrm{R}^{2}\right)$ were determined for each one of the three models, e.g. the dry longitudinal wave velocity versus the dry density, the point load strength index versus the dry density, and finally the point load strength index versus the dry longitudinal wave velocity.

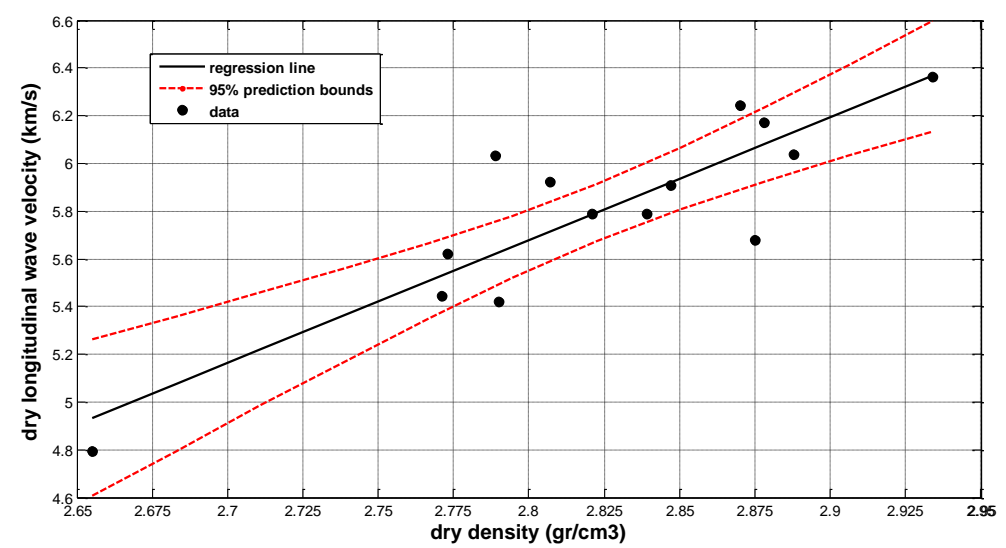

Figure 7 - Dry longitudinal wave velocity versus dry density.

The relationship between the dry density $\rho_{\mathrm{d}}\left(\mathrm{in} \mathrm{gr} / \mathrm{cm}^{3}\right)$ and the dry longitudinal wave velocity $\mathrm{v}_{\mathrm{l}}$ (in $\mathrm{km} / \mathrm{s}$ ) was found to be linear (Fig. 7). Density is thought to be the principal factor affecting the velocity of longitudinal waves and in general their correlation is of a linear form (Lama and Vutukuri, 1978).

The equation of the line is:

$$
v_{l}=5.135 * \rho_{d}-8.701 \quad \mathbf{R}^{2}=0.76
$$

The $\pm 95 \%$ prediction bounds for the slope and the intercept are $(3.329,6.942)$ and $(-13.8,-3.598)$ respectively.

The point load strength index (in dry conditions) Is $(50)$, (in MPa), exhibits a linear increase with the increase in dry density (Fig. 8).

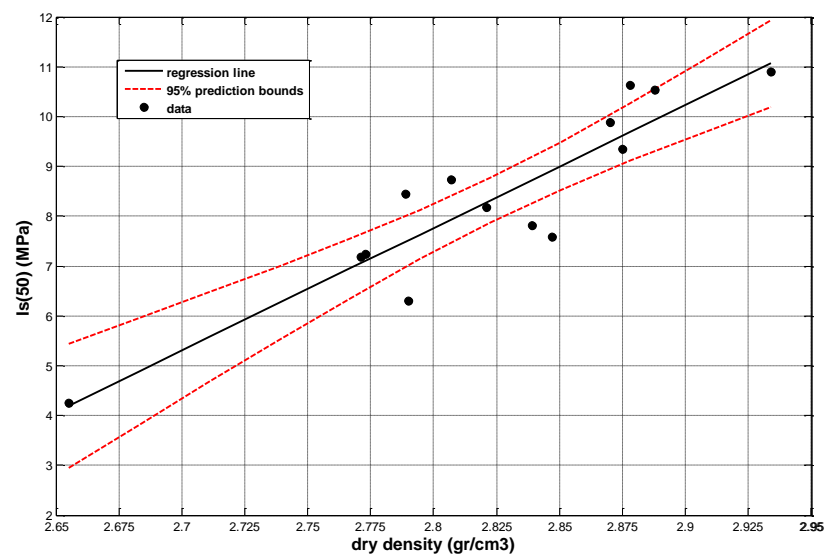

Figure 8 - Is $\mathbf{s}_{(50)}$ versus dry density.

The equation of the line is: 


$$
I_{(50)}=24.62 * \rho_{d}-61.17 \quad \mathbf{R}^{2}=0.84
$$

The $\pm 95 \%$ prediction bounds for the slope and the intercept are $(17.8,31.44)$ and $(-80.44,-41.9)$ respectively.

In the same manner, the point load strength index $\mathrm{Is}_{(50)}$, shows a linear increase with the increase in dry longitudinal wave velocity (Fig. 9).

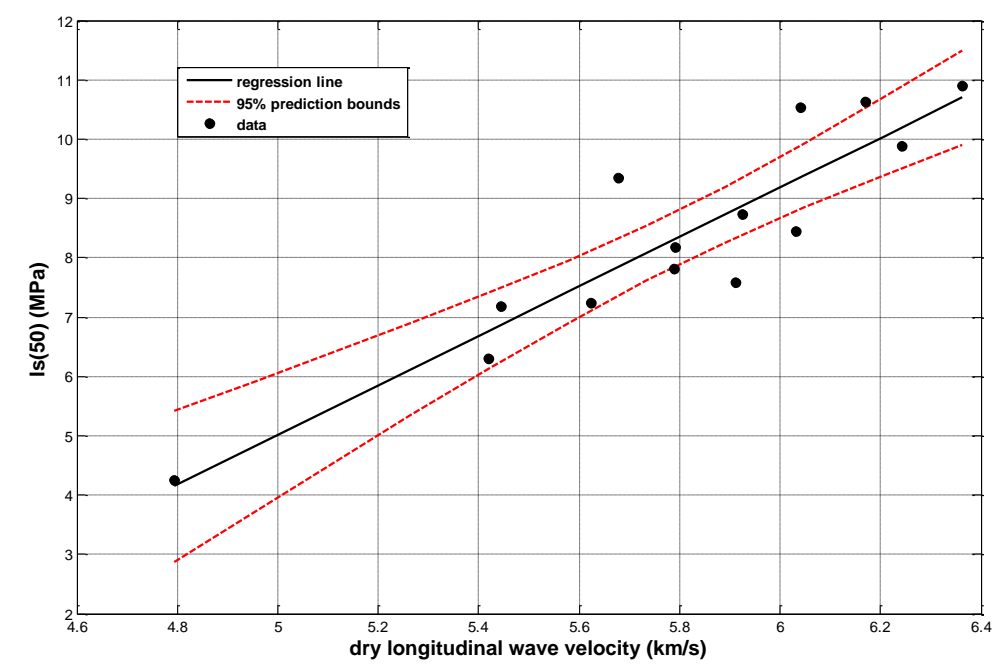

Figure 9 - Is(50) versus dry longitudinal wave velocity.

In this case the equation of the line is:

$$
I_{(50)}=4.173 * v_{l}-15.85 \quad \mathbf{R}^{2}=\mathbf{0 . 8 3}
$$

The $\pm 95 \%$ prediction bounds for the slope and the intercept are $(2.999,5.348)$ and $(-22.68,-9.025)$ respectively.

\section{Statistical Significance of The Results}

The significance of the regression coefficients was determined via the t-test. This test examines if the null hypothesis, which states that the regression coefficient is zero, is truth. If the computed tvalues are greater than the tabulated t-values, the null hypothesis is rejected. For $95 \%$ confidence level, the critical t-value for the derived models is \pm 2.18 . The calculated $t$-values are summarized in Table 5. As seen the computed t-values are greater than the tabulated ones, so the linear correlations between the variables are real.

Table 5 - Significance of the coefficients.

\begin{tabular}{|c|c|c|}
\hline Equation No. & t-computed & t-critical \\
\hline 1 & 6.19 & \pm 2.18 \\
\hline 2 & 7.88 & \pm 2.18 \\
\hline 3 & 7.74 & \pm 2.18 \\
\hline
\end{tabular}




\section{Conclusions}

Laboratory tests were carried out for the determination of the dry density, the dry longitudinal wave velocity and the axial point load strength index for the petrological type of prasinites (metabasites). A linear relationship between the physical properties was established. The point load strength index was found to increase linearly with the increase in both of the physical properties.

The correlations exhibits strong coefficients of determination and proved to be statistically significant. The above equations can be used from the geoscientists, who deal with geotechnical problems occupied in the study area, but also in the case of other areas, where prasinites with similar structural characteristics, outcrop.

\section{Acknowledgments}

We would like to thank Kotsanis Stauros for his contribution to the field work.

\section{References}

Altindag, R., 2012. Correlation between P-wave velocity and some mechanical properties for sedimentary rocks, J. South. Afr. Inst. Min. Metall., 122, 229-237.

Anon, 1979a. Classification of rocks and soils for engineering geological mapping. Part 1 - Rock and soil material, Bull. Int. Assoc. Geo., 19, 364-371.

Augustinus, P.C., 1991. Rock resistance to erosion: Some further considerations, Earth Surf. Process. Landf., 16, 563-569.

Aydin, A., 2015. The ISRM Suggested Methods for Rock Characterization, Testing and Monitoring. In: Ulusay, R., eds., 2007 - 2014, 25-33, Wien, Springer Verlag, 293 pp.

Baziotis, I., Proyer, A. and Mposkos, E., 2008. High-pressure/Low-temperature metamorphism of metabasites in Lavrion area (SE Attica, Greece): implications for the preservation of peak metamorphic assemblages in blueschists and greenschists, Eur. J. Mineral., 21, 133-148.

Beavis, F.C., 1985. Engineering geology, Melbourne, Blackwell Scientific, 231 pp.

Bieniawski, Z.T., 1975. Point load test in geotechnical practice, Eng. Geol., 9(1), 1-11.

Bieniawski, Z.T., 1989. Engineering RockMass Classifications: A Complete Manual for Engineers and Geologists in Mining, Civil and Petroleum Engineering, New York, John Wiley and Sons, Inc., $272 \mathrm{pp}$.

Broch, E. and Franklin, J.A., 1972. The Point Load Strength Test, Int. J. Rock. Mech. Min. Sci., 9, 669-697.

Fener, M., Kahraman, S., Bilgil, A. and Gunaydin, O., 2005. A Comparative Evaluation of Indirect Methods to Estimate the Compressive Strength of Rocks, Rock Mech. Rock Engng., 38(4), 329-343.

Guidicini, G., Nieble, C.M. and Cornides, A.T., 1973. Analysis of point load test as a method for preliminary geotechnical classification of rocks, Bull. Int. Assoc. Eng. Geol., 7, 37-52.

Gupta, A.S. and Seshagiri Rao, K., 1998. Index properties of weathered rocks: inter-relationships and applicability, Bull. Eng. Geol. Env., 57, 161-172.

Irfan, T.Y. and Dearman, W.R., 1978. Engineering classification and index properties of a weathered granite, Bull. Int. Assoc. Eng. Geol., 17, 79-90.

ISRM, 1981a. Rock characterization testing and monitoring. Suggested method. In: Brown, E.T., eds., London, Pergamon Press, 221 pp.

ISRM, 1985b. Suggested methods for determining the point load strength. Int. Soc. for Rock Mech., Commission on Testing Methods; Working Group on Revision of the Point Load Test Methods, Int. J. Rock Mech. Min. Sci. Geomech. Abstr., 22, 51-60.

Kahraman, S. and Gunaydin, O., 2009. The effect of rock classes on the relation between uniaxial compressive strength and point load index, Bull. Eng. Geol. Environ., 68, 345-353.

Katsikatsos, G., 1992. Geology of Greece, Athens, Patras University Publications, 451 pp. 
Kurtulus, C., Bozkurt, A. and Endes, H., 2012. Physical and Mechanical Properties of Serpentinized Ultrabasic Rocks in NW Turkey, Pure Appl. Geophys., 169(7), 1205-1215.

Lama, R.D. and Vutukuri, V.S., 1978. Handbook on Mechanical Properties of Rocks - Volume II, Clausthal, Germany, Trans Tech Publications, $481 \mathrm{pp}$.

Palchik, V. and Hatzor, Y.H., 2004. The Influence of Porosity on Tensile and Compressive Strength of Porous Chalks, Rock Mech. Rock Engng., 37(4), 331-341.

Pasamehmetoglu, A.G., Karpuz, C. and Irfan, T.Y., 1981. The weathering classification of Ankara andesites from rock mechanics point of view, Proc, Int. Symp. Weak Rocks, Tokyo, 1, 185-190.

Rozos, D., 1989. Engineering Geological conditions in Achaia Country. Geomechanical characteristics of Plio - Pleistocene sediments, Phd Thesis, Department of Geology, University of Patras, $453 \mathrm{pp}$.

Shafiei, A., Heidari, M. and Dusseault, M.B., 2007. Rock Mechanics Meeting Society's Challenges and Demands. In: Eberhardt, E., Stead, D. and Morrison, T., eds., Volume 1: Fundamentals, New Technologies \& New Ideas, 835-842, London, Taylor \& Francis Group, 1772 pp. 